\title{
Endoscopic Lung Volume Reduction Using Endobronchial Valves in Patients with Severe Emphysema and Very Low FEV $_{1}$
}

\author{
Franziska C. Trudzinski ${ }^{a}$ Anna J. Höink ${ }^{e}$ Daniela Leppert ${ }^{b}$ \\ Sebastian Fähndrich $^{a}$ Heinrike Wilkens ${ }^{a}$ Thomas P. Graeter ${ }^{f}$ Frank Langer $^{c}$ \\ Robert Bals ${ }^{a}$ Peter Minko ${ }^{d}$ Philipp M. Lepper ${ }^{a}$ \\ Departments of ${ }^{\mathrm{a}}$ Internal Medicine V - Pneumology, Allergology and Critical Care Medicine, ${ }^{\mathrm{b}}$ Nuclear Medicine, \\ ${ }^{\mathrm{C}}$ Thoracic and Cardiovascular Surgery and ${ }^{\mathrm{d}}$ Diagnostic and Interventional Radiology, Saarland University Medical \\ Center, Homburg, ${ }^{e}$ Department of Diagnostic and Interventional Radiology, HELIOS Klinikum Krefeld, Krefeld, and \\ fDepartment of Thoracic and Vascular Surgery, Klinikum Löwenstein, Löwenstein, Germany
}

\section{Key Words}

Endoscopic lung volume reduction - Endobronchial valves . Severe emphysema

\begin{abstract}
Background: Patients with a forced expiratory volume in $1 \mathrm{~s}\left(\mathrm{FEV}_{1}\right)$ below $20 \%$ of the predicted normal values (pred.) and either homogeneous emphysema or low diffusing capacity for carbon monoxide (DLCO) have a high risk for adverse events including death when undergoing surgical lung volume reduction. Objectives: We hypothesized that selected patients can benefit from endoscopic lung volume

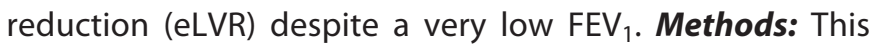
study is a retrospective analysis of consecutive patients with severe airflow obstruction, an $\mathrm{FEV}_{1} \leq 20 \%$ of pred., and low DLCO who were treated by eLVR with endobronchial valves (EBV) between June 2012 and January 2015. Pre- and postinterventional lung function parameters, the 6-min walking test (6-MWT) distance, adverse events, and follow-up were
\end{abstract}

recorded. Results: In 20 patients, there was an overall improvement in lung function with an increase in $\mathrm{FEV}_{1}$ (16.97$21.03 \%$ of pred.) and a decrease in residual volume (322$270 \%$ of pred.) and total lung capacity (144-129.06\% of pred.). The 6-MWT distance improved (from $239 \pm 77$ to $267 \pm 97 \mathrm{~m}$ overall, and from $184 \pm 50$ to $237 \pm 101 \mathrm{~m}$ if patients developed an atelectasis of the target lobe). Pneumothorax occurred in 5 of the 20 patients (25\%). 30-day mortality was $0 \%$, and all patients survived to discharge. Conclusions: The patients benefitted moderately from EBV treatment despite an initially low $\mathrm{FEV}_{1}$. Some patients improved remarkably. EBV treatment in patients with an $\mathrm{FEV}_{1}$ $\leq 20 \%$ of pred. is generally feasible and safe. The greatest risk is pneumothorax with prolonged chest tube duration.

(c) 2016 S. Karger AG, Basel

A.J.H. and D.L., as well as P.M. and P.M.L., contributed equally to this paper.

\section{KARGER}

E-Mail karger@karger.com

www.karger.com/res
(C) 2016 S. Karger AG, Basel

0025-7931/16/0924-0258\$39.50/0 


\section{Introduction}

When patients with chronic obstructive pulmonary disease (COPD) develop severe emphysema associated with a reduced gas exchange area, pharmacologic therapy offers only few advantages. Hence, the therapy options are very limited for these patients. All therapeutic options except lung transplantation have a palliative character. Even if COPD patients are listed for lung transplantation, effective therapies are still needed to ameliorate their symptoms, as the waiting time on the transplant list is long and these patients rarely gain high priority on the waiting list.

Surgical lung volume reduction (sLVR) has been shown to improve lung function and quality of life in palliative care as well as in patients waiting for lung transplantation [1-4]. Nevertheless, the procedure has relevant risks, and not all patients are suitable to undergo sLVR. The National Emphysema Treatment Trial (NETT) showed high mortality rates within the first 30 days for patients with a low forced expiratory volume in $1 \mathrm{~s}\left(\mathrm{FEV}_{1}\right)$ and either homogeneous emphysema or a very low diffusing capacity for carbon monoxide (DLCO) $[4,5]$. Nevertheless, longterm follow-up of the high-risk patients of the NETT ultimately showed a benefit even in this subgroup [5].

Several studies have shown that endoscopic lung volume reduction (eLVR) with endobronchial valves (EBV) is an effective treatment for patients with emphysema. eLVR mimics basic principles of sLVR with a less invasive and fully reversible approach [6-8].

We hypothesized that eLVR provides a treatment option for patients meeting the NETT criterion for high risk; therefore we analyzed patients with a very low $\mathrm{FEV}_{1}$ and very low DLCO undergoing eLVR in our institution.

\section{Methods}

Study Design and Participants

This study is a retrospective analysis of consecutive patients with severe airflow obstruction, an $\mathrm{FEV}_{1} \leq 20 \%$ of predicted (pred.), and a low DLCO who were treated by eLVR between March 2012 and March 2015. From a computerized database, we retrieved all patients with severe emphysema and COPD GOLD stages IIIIV referred to our department at the Saarland University Medical Center for eLVR. All patients were treated according to an institutional protocol to ensure a standardized procedure.

All patients had previously smoked cigarettes, but our protocol requested patients to have quit more than 3 months before the intervention. One prerequisite for treatment was established maximal pharmacological treatment (minimum: long-acting beta agonist, long-acting muscarinic antagonists, and inhaled corticosteroid). Pulmonary rehabilitation was not a prerequisite for treatment.
In this cohort, per protocol, every patient except 1 received 5 days of antibiotic treatment [sultamicillin $(2 \times 375 \mathrm{mg}$ b.i.d. $)$ and $50 \mathrm{mg}$ prednisolone peri-interventionally]. We included all patients that had an $\mathrm{FEV}_{1} \leq 20 \%$ of pred. and DLCO $<20 \%$ of pred. into this analysis. Homogeneous distribution of emphysema was not an exclusion criterion to treatment unless perfusion scintigraphy or SPECT/CT also showed a homogeneous distribution of perfusion, rendering the selection of a target lobe impossible. Before the procedure, all patients underwent functional testing including lung function, the 6-min walking test (6-MWT), DLCO (if possible), and blood gas analysis.

Acute exacerbation was excluded clinically and in laboratory analyses. Ventilation and perfusion scintigraphy (V/Q scanning) or perfusion scanning only and CT were assessed prior the intervention. Assessment of collateral ventilation $(\mathrm{CV})$ was additionally performed to determine the target lobe. CV was measured using a catheter system (Chartis ${ }^{\mathrm{TM}}$; PulmonX, Redwood City, Calif., USA) during the same bronchoscopy procedure prior to the intervention.

Successful eLVR was defined as atelectasis on chest X-ray or CT. The clinical benefit from functional changes was defined by the minimal clinically important difference (MCID) between follow-up and baseline. The MCID for $\mathrm{FEV}_{1}$ was reached at an increase of $100 \mathrm{ml}$ [9], for residual volume (RV) it was reached with a 430- $\mathrm{ml}$ reduction [10], and for the 6-MWT distance if there was an increase of $>26 \mathrm{~m} \mathrm{[11].}$

Patients were discharged in clinically stable condition at least 4 days following eLVR. Follow-up for the current analysis was scheduled 4-6 weeks after the procedure. The study was approved by the institutional review board (Ärztekammer des Saarlandes; No. $35 / 15)$. The necessity for informed consent was waived by the institutional review board due to the retrospective nature of the study.

\section{Pulmonary Function Tests and 6-MWT}

Pulmonary function tests were performed with a Jaeger MasterScreen Body System (CareFusion, Rolle, Switzerland); static lung volumes were determined by whole-body plethysmography. DLCO was measured by using the single-breath technique. All measurements were performed according to the American Thoracic Society (ATS) and the European Respiratory Society (ERS) guidelines [12-14].

The 6-MWT was measured in all patients on a 70-meter floor after providing standard instructions [15]. The patients were not encouraged during the test [16]. All patients were familiar with the 6-MWT before study entry. During the 6-MWT, supplemental oxygen was administered through a nasal cannula as needed to maintain the arterial oxygen saturation at $\geq 90 \%$. These standards were kept before and after eLVR.

\section{Procedure}

Bronchoscopy and periprocedural preparations were performed according to our internal standard. All interventions were performed under total intravenous anesthesia. The patients were intubated and mechanically ventilated.

Valves (Zephyr EBV; PulmonX) were placed unilaterally in lobar, segmental, or subsegmental bronchi based on the individual anatomic conditions with the intention of completely isolating the target lobe. Valves are available in two sizes, spanning airway diameters of $4.0-7.0$ and $5.5-8.5 \mathrm{~mm}$. All patients underwent a chest $\mathrm{X}$-ray $1 \mathrm{~h}$ after the procedure (or earlier if symptoms occurred) to exclude a pneumothorax. In analogy to a surgical approach, 13/20 patients $(65 \%)$ were treated bilaterally, but staged ( 2 patients re- 
Table 1. Baseline characteristics of the patients undergoing eLVR

\begin{tabular}{|c|c|}
\hline \multicolumn{2}{|l|}{ Clinical presentation } \\
\hline Age, years & $57.21 \pm 6.22$ \\
\hline Male & $11 / 20(55)$ \\
\hline BMI & $21.57 \pm 4.1$ \\
\hline BODE index & $7 \pm 1.41$ \\
\hline Listed for LTX at time of intervention & $5 / 20(25)$ \\
\hline Currently listed for LTX & $8 / 20(40)$ \\
\hline Mean LAS & $34.98 \pm 5.45(25.09-46.30)$ \\
\hline \multicolumn{2}{|l|}{ Arterial blood gas } \\
\hline $\mathrm{PaO}_{2}<55 \mathrm{~mm} \mathrm{Hg}$ and/or LTOT & $19 / 20(95)$ \\
\hline $\mathrm{PaCO}_{2}>50 \mathrm{~mm} \mathrm{Hg}$ & $8 / 20(40)$ \\
\hline 6-MWT distance ${ }^{\mathrm{a}}, \mathrm{m}$ & $249 \pm 102(86-448)$ \\
\hline DLCO $<20 \%$ of pred. ${ }^{b}$ & $17 / 17(100)$ \\
\hline \multicolumn{2}{|l|}{ Baseline lung function } \\
\hline \multicolumn{2}{|l|}{$\mathrm{FEV}_{1}$} \\
\hline Liters & $0.50 \pm 0.13(0.30-0.74)$ \\
\hline Percent of pred. & $16.99 \pm 2.61(11-20)$ \\
\hline \multicolumn{2}{|l|}{ Vital capacity } \\
\hline Liters & $1.80 \pm 0.77(0.61-3.61)$ \\
\hline Percent of pred. & $47.36 \pm 12.98(27-73)$ \\
\hline \multicolumn{2}{|l|}{ RV } \\
\hline Liters & $6.79 \pm 1.50(3.61-9.63)$ \\
\hline Percent of pred. & $322.51 \pm 75.42(232-577)$ \\
\hline \multicolumn{2}{|l|}{ TLC } \\
\hline Liters & $8.55 \pm 1.92(4.22-12.20)$ \\
\hline Percent of pred. & $144.53 \pm 25.33(110-213)$ \\
\hline RV/TLC, \% & $78.29 \pm 6.03(63-85)$ \\
\hline \multicolumn{2}{|c|}{$\begin{array}{l}\text { Values are presented as } \mathrm{n}(\%) \text { or means } \pm \mathrm{SD} \text { (range). BMI = Body mass index; } \\
\text { BODE = body mass index, airflow obstruction, dyspnea and exercise capacity [29]; } \\
\text { LTX = lung transplantation; LAS = lung allocation score; LTOT = long-term oxygen } \\
\text { therapy; } \mathrm{PaO}_{2}=\text { partial pressure of oxygen; } \mathrm{PaCO}_{2}=\text { partial pressure of carbon dioxide. } \\
\text { a } \mathrm{n}=17 \text {. }{ }^{\mathrm{b}} \mathrm{Diffusing} \text { capacity was available in } 17 \text { cases; in } 3 \text { patients, vital capacity was too } \\
\text { low to exactly determine DLCO. }\end{array}$} \\
\hline
\end{tabular}

ceived LVR coils due to CV on one side and EBV on the other side). We included only the first EBV procedure in this analysis to avoid interdependence. All reported outcome data were taken prior to a possible second treatment.

\section{Statistical Analysis}

Statistical analysis was performed using SPSS version 21 (SPSS Inc., Chicago, Ill., USA). Data were analyzed using Wilcoxon's signed-rank test. Results were considered statistically significant for $\mathrm{p}$ values $<0.05$.

\section{Results}

\section{Baseline Characteristics of the Study Population}

Twenty emphysema patients who fulfilled the abovementioned criteria underwent eLVR at our center. Their baseline characteristics are shown in table 1 . The mean
$\mathrm{FEV}_{1}$ was $0.50 \pm 0.13(0.30-0.74)$ liters, equaling $16.99 \pm$ $2.6 \%$ of pred. at a total lung capacity (TLC) of $8.55 \pm 1.92$ (4.22-12.20) liters and $144.50 \pm 25.33 \%$ of pred. RV was $6.80 \pm 1.50$ (3.61-9.63) liters, equaling $322.50 \pm 75.40 \%$ of pred.; thus the RV/TLC ratio was increased to $78.29 \pm$ $6.03 \%$ of pred. The BODE index was $7.0 \pm 1.41$. The majority of the patients $(19 / 20 ; 95 \%)$ had low partial pressure of oxygen; 8 patients (40\%) showed chronic respiratory failure with elevated partial pressure of carbon dioxide. The diffusing capacity was available in 17 cases (85\%), and the DLCO was $<20 \%$ pred. in all of them. In 3 patients, vital capacity was too low to exactly determine the DLCO. Presumably, their DLCO was $<20 \%$ pred. as well.

At the time of the intervention, 5 patients (25\%) were listed for lung transplantation. At the present time, 8 patients (40\%) in this group are listed, and 1 patient has undergone lung transplantation. 
Table 2. Collateral ventilation, treated lobe, and radiologic response

\begin{tabular}{|c|c|c|c|c|}
\hline & Patients & PTX & Atelectasis & $\begin{array}{l}\text { Atelectasis with or } \\
\text { without PTX }\end{array}$ \\
\hline \multicolumn{5}{|c|}{ Collateral ventilation according to Chartis } \\
\hline Positive & $1 / 20(5)$ & $0 / 1(0)$ & $0 / 1(0)$ & $0 / 2(0)$ \\
\hline Negative & $17 / 20(85)$ & $5 / 17(29.4)$ & $6 / 17(35)$ & $11 / 17(55)$ \\
\hline Likely negative & $2 / 20(10)$ & $0 / 2(0)$ & $0 / 2(0)$ & $0 / 2(0)$ \\
\hline \multicolumn{5}{|l|}{ Target lobe } \\
\hline LUL & $7 / 20(35)$ & $3 / 7(42.9)$ & $2 / 7(28.6)$ & $5 / 7(71.4)$ \\
\hline LLL & $5 / 20(25)$ & $2 / 5(40)$ & $1 / 5(20)$ & $3 / 5(60)$ \\
\hline RUL & $5 / 20(25)$ & $0 / 5(0)$ & $3 / 5(60)$ & $3 / 5(60)$ \\
\hline RLL & $3 / 20(15)$ & $0 / 3(0)$ & $0 / 3(0)$ & $0 / 3(0)$ \\
\hline \multicolumn{5}{|c|}{ Emphysema distribution $^{\mathrm{a}}$} \\
\hline Homogeneous & $13 / 20(45)$ & $3 / 9(33.3)$ & $1 / 9(16.7)$ & $4 / 9(44.4)$ \\
\hline Heterogeneous & $7 / 20(55)$ & $2 / 11(18.2)$ & $5 / 11(45.5)$ & $7 / 11(63.6)$ \\
\hline
\end{tabular}

Values are presented as $\mathrm{n}(\%)$. Radiologic response is defined as presence of atelectasis in the target lobe or postinterventional pneumothorax. PTX = Pneumothorax; LUL = left upper lobe; LLL = left lower lobe; RUL = right upper lobe; $\mathrm{RLL}=$ right lower lobe. ${ }^{\text {a }}$ Emphysema distribution is according to interventional pneumologists.

\section{Emphysema Distribution and CV}

The preinterventional CT scan showed a homogeneous emphysema distribution in 9 cases (45\%). All patients had heterogeneous perfusion as shown by the V/Q scan or SPECT/CT.

$\mathrm{CV}$ could be excluded by Chartis ${ }^{\mathrm{TM}}$ measurement in 17 patients (85\%). In 2 cases (10\%), our measurement yielded no definitive result, as airways had collapsed, and in 1 case we found evidence for minimal residual CV. The results of the Chartis ${ }^{\mathrm{TM}}$ measurements are shown in table 2 .

\section{Interventional Treatment and Adverse Events}

The most frequently treated lobe was the left upper lobe $(7 / 20 ; 35 \%)$, followed by the left lower and the right upper lobe $(5 / 20 ; 25 \%)$. A pneumothorax occurred in 5 cases (25\%). All pneumothoraces were located on the left side. Three of the 5 occurred following left upper lobe treatment.

The patients who developed a pneumothorax showed mixed clinical courses. The majority had a prolonged air leak of a mean duration of $21.8 \pm 12.4$ days. Pneumothoraces occurred within $24 \mathrm{~h}$ following the intervention in all cases.

We had to remove the valves in 2 cases due to persisting air leaks after 6 and 35 days, respectively. The valve extraction after 6 days was due to a major air leak. After valve removal, the patient was on a chest tube for another 27 days. These 2 patients showed a clinical deterioration with both a decline in their lung function and the 6-MWT distance. The other 3 patients benefitted from EBV treat-
Table 3. Adverse events

$\begin{array}{ll}\text { Pneumothorax } & 5 / 20(25) \\ \text { Pneumothorax } \geq 14 \text { days } & 3 / 5(60) \\ \text { Duration of chest tube, days } & 22.2 \pm 12.42(10-41) \\ \text { Additional chest tube } & 2 / 5(40) \\ \text { Repeated pneumothorax } & 1 / 5(20) \\ \text { Valves removed } & 2 / 20(10) \\ \text { Mild exacerbation after bronchoscopy } & 3 / 20(15) \\ \text { Pneumonia } & 0 / 20(0) \\ \text { Valve migration } & 0 / 20(0)\end{array}$

Values are presented as $\mathrm{n}(\%)$ or mean $\pm \mathrm{SD}$ (range).

ment despite drainage times between 8 and 14 days. One patient developed a pneumothorax ipsilateral to the treated lobe 768 days after the procedure. This event was not rated as a procedure-associated pneumothorax. Six patients $(30 \%)$ developed an atelectasis without occurrence of a pneumothorax (table 3 ).

No pneumonia occurred after EBV placement. No valve migration or loss of valves occurred. All patients survived the treatment; the 30 -day mortality was $0 \%$.

\section{Functional Results of Interventional Treatment}

There was an overall improvement in lung function with an increase in $\mathrm{FEV}_{1}$ and a decrease in RV and TLC. Subsequently, there was a reduction of the RV/TLC ratio, as shown in table 4. 
Table 4. Functional characteristics of the patients prior to and after eLVR

\begin{tabular}{|c|c|c|c|c|c|}
\hline & Baseline & Follow-up & $\Delta$ & $\mathrm{p}$ & Responder rate \\
\hline $\mathrm{FEV}_{1}, 1$ & $0.50 \pm 0.13 ; 0.51$ & $0.61 \pm 0.15 ; 0.61$ & $+0.11 \pm 0.15 ;+0.04$ & 0.001 & $5 / 20(25.0)$ \\
\hline $\mathrm{FEV}_{1}, \%$ & $16.99 \pm 2.61 ; 18.00$ & $21.05 \pm 6.71 ; 19.35$ & $+4.06 \pm 6.94 ;+1.25$ & 0.001 & - \\
\hline VC, 1 & $1.80 \pm 0.77 ; 1.69$ & $1.89 \pm 0.47 ; 1.94$ & $+0.10 \pm 0.64 ;+0.17$ & 0.227 & - \\
\hline VC, \% & $47.36 \pm 12.98 ; 46.75$ & $52.35 \pm 13.31 ; 49.60$ & $+5.00 \pm 16.73 ;+6.50$ & 0.126 & - \\
\hline TLC, 1 & $8.55 \pm 1.92 ; 8.63$ & $7.85 \pm 2.38 ; 7.78$ & $-0.73 \pm 1.68 ;-0.46$ & 0.070 & - \\
\hline TLC, \% & $144.53 \pm 25.33 ; 140.05$ & $129.07 \pm 19.20 ; 124.00$ & $-14.85 \pm 30.76 ;-6.10$ & 0.059 & - \\
\hline RV/TLC & $78.29 \pm 6.03 ; 79.46$ & $75.86 \pm 0.74 ; 75.70$ & $-2.23 \pm 9.57 ;-0.22$ & 0.376 & - \\
\hline 6-MWT dist., $\mathrm{m}$ & $239.65 \pm 76.73 ; 240.00$ & $267.45 \pm 98.35 ; 275.00$ & $+50 \pm 0.51 ;+50.00$ & 0.191 & $10 / 20(50.0)$ \\
\hline
\end{tabular}

Values are presented as 'means $\pm \mathrm{SD}$; medians' or $\mathrm{n}(\%) . \mathrm{n}=20$ patients, time to follow-up was $4-6$ weeks. In 1 patient, whole-body plethysmography could not be performed for follow-up. $\Delta$ Differences between before and after treatment. Responder rate: the number of patients for whom the change met or exceeded the MCID for FEV (increase of $>100 \mathrm{ml}$ ), RV (decrease of $>430 \mathrm{ml}$ ), and 6-MWT distance (increase of $>26 \mathrm{~m}$ ). $\mathrm{p} \leq 0.05$ for Wilcoxon's signed-rank test was considered statistically significant (in italics). VC $=$ Vital capacity; dist. $=$ distance.

Table 5. Functional characteristics of the patients prior to and after eLVR according to the different emphysema distribution and development of atelectasis

\begin{tabular}{|c|c|c|c|c|c|c|}
\hline & $\begin{array}{l}\text { Homogeneous } \Delta \\
(\mathrm{n}=9)\end{array}$ & $\begin{array}{l}\text { Homogeneous } \\
\text { responder rate }\end{array}$ & $\begin{array}{l}\text { Heterogeneous } \Delta \\
(\mathrm{n}=11)\end{array}$ & $\begin{array}{l}\text { Heterogeneous } \\
\text { responder rate }\end{array}$ & $\begin{array}{l}\text { Atelectasis } \Delta \\
(\mathrm{n}=9)\end{array}$ & $\begin{array}{l}\text { Atelectasis } \\
\text { responder rate }\end{array}$ \\
\hline $\mathrm{FEV}_{1}, 1$ & $+0.07 \pm 0.08 ;+0.06$ & $1 / 9(11.1)$ & $+0.15 \pm 0.19 ;+0.03$ & 4/11 (36.4) & $+0.14 \pm 20 ; 0.03$ & $3 / 9(33.3)$ \\
\hline VC, 1 & $-0.08 \pm 0.78 ;+0.19$ & - & $+0.24 \pm 0.49 ;+0.14$ & - & $+0.23 \pm 0.81 ; 0.39$ & - \\
\hline $\mathrm{VC}, \%$ & $+0.99 \pm 18.87 ;+8.5$ & - & $+8.27 \pm 14.86 ;+4.50$ & - & $+10.24 \pm 20.83 ; 15.40$ & - \\
\hline $\mathrm{RV}, \%$ & $-28.08 \pm 130.40 ;-1.00$ & - & $-69.18 \pm 59.41 ;-55.50$ & - & $-77.09 \pm 124.65 ;-58.80$ & - \\
\hline TLC, 1 & $-0.57 \pm 1.82 ;-0.27$ & - & $-0.87 \pm 1.61 ;-1.13$ & - & $-1.22 \pm 1.71 ;-0.94$ & - \\
\hline TLC, \% & $-11.07 \pm 36.20 ;-5.70$ & - & $-18.26 \pm 26.47 ;-18.35$ & - & $-23.60 \pm 35.51 ; 14.40$ & - \\
\hline RV/TLC & $+2.10 \pm 9.50 ;+2.93$ & - & $-6.11 \pm 8.21 ;-6.27$ & - & $-5.40 \pm 11.89 ;-7.95$ & - \\
\hline 6-MWT & $2167+6250.25$ & $510(55)^{2}$ & $04<0102-0$ & $5 / 11(455)$ & & 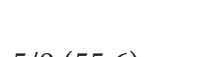 \\
\hline
\end{tabular}

Values are presented as 'means \pm SD; medians' or $\mathrm{n}(\%)$. In the group of patients with atelectasis, 2 patients were excluded, as valves had to be removed. In 1 patient, whole-body plethysmography could not be performed for follow-up. $\Delta$ Differences between before and after treatment. Responder rate: the number of patients for whom the change met or exceeded the $\mathrm{MCID}_{\text {for }} \mathrm{FEV} \mathrm{V}_{1}$ (increase of $>100$ $\mathrm{ml}$ ), RV (decrease of $>430 \mathrm{ml}$ ), and 6-MWT distance (increase of $>26 \mathrm{~m}$ ). dist. $=$ Distance.

Eleven of 19 patients (55\%) developed an atelectasis of the target lobe. The MCID for $\mathrm{FEV}_{1}$ (l) was reached in $5 / 20$ cases (25\%), for RV (l) in $11 / 19$ cases (57.9\%), and for 6-MWT distance in 10/20 cases (50\%).
Next, we analyzed the functional response differentially regarding emphysema distribution. Patients with homogeneous emphysema distribution showed a weaker lung functional response to treatment; the MCID for $\mathrm{FEV}_{1}$ (l) was reached in $11.1 \%$, and only $44.4 \%$ of the pa- 
tients showed a relevant reduction in RV (1). Greater improvement was seen in the patients with heterogeneous emphysema distribution. These patients benefitted in terms of $\mathrm{FEV}_{1}$ (l) in $36.4 \%$ and in terms of RV (l) in $70 \%$ of the cases. Patients with atelectasis were comparable to patients with heterogeneous emphysema distribution regarding their lung functional response (table 5). In the 6-MWT, all patients improved across the different groups with a relevant overall improvement in $50 \%$ of the cases and in $55.6,45.5$, and $55.6 \%$, respectively, within the three subgroups (tables 4,5 ).

\section{Discussion}

This retrospective analysis of 20 carefully selected patients with high-risk criteria according to the NETT [17] showed that eLVR improves lung function and exercise capacity in individual patients. The main complications were pneumothoraces. All patients survived to discharge. Short-term complications were of lesser importance compared to the reported $16 \% 30$-day mortality among high-risk patients following sLVR [5].

The only nonpalliative treatment option for end-stage COPD patients is lung transplantation. Most patients do not qualify for transplantation, and the demand for organs exceeds their availability by far. As these patients usually remain symptomatic despite optimal conservative treatment, there is a great need for therapies that actually improve the burden of symptoms [18].

Hyperinflation and expiratory airflow limitation play a key role in dyspnea and functional limitations [19]. Both surgical and endoscopic techniques target and improve these parameters $[2,4,6-8]$. The NETT, while showing the efficacy of the method, might have led to an underuse of sLVR due to surgical morbidity and mortality $[4,17]$. Hence, there is a quest for minimally invasive techniques that can produce significant functional, quality-of-life, and survival benefits for patients with severe COPD. There might be a trend towards an overuse of endoscopic methods, and clearly defined strategies for patient selection are still lacking.

The most hazardous complication in the first randomized trial of eLVR using EBV - besides increased rates of exacerbations, hemoptysis, and pneumonia - was the development of a pneumothorax (at a rate of 4.2\%) [6]. This proportionally low rate of pneumothoraces is caused by a low rate of complete fissures, leading to CV and incomplete lobar occlusion [20]. Due to an improved patient selection in consideration of catheter-based CV assess- ment [21-24] and CT-based analysis [24, 25], the rate of pneumothoraces increases up to $25-30 \%$, as in the current analysis.

Pneumothorax following eLVR is a potentially lethal complication in these frail patients. Prolonged air leaks are reported in $68 \%$ of cases [23]. The current recommendation to remove valves stepwise following a chest tube duration longer than 9 days may dilute the success of eLVR in this group of patients [26]. The majority of patients in our cohort had an air leak for more than 14 days. We had to remove the valves in 2 cases due to persisting air leaks, but all patients could be managed conservatively by chest tube.

Our patients showed a moderate improvement after eLVR. Despite a mean volume reduction of -1.1 liters RV and a responder rate of $57.9 \%$ regarding $\mathrm{RV}(\mathrm{l})$, the MCID for $\mathrm{FEV}_{1}$ (l) was only reached for $25 \%$ of the patients, and only $50 \%$ improved their 6 -MWT distance above the MCID.

The subgroups with heterogeneous emphysema distribution and atelectasis presented higher response rates: up to $33.3-36 \%$ regarding $\mathrm{FEV}_{1}$ (l) and 55.6-70\% regarding RV (1). The mean RV reduction in heterogeneous and atelectasis patients was 1.46 and 1.45 liters, respectively. Nevertheless, the 6-MWT response rate within these subgroups was still only 45 and 55.6\%, respectively.

If we compare our cohort to a very similar cohort undergoing sLVR fulfilling high-risk criteria according to the NETT, it has to be stated that the lung functional and exercise results exceed the currently reported interventional results by far [27]. This is true despite the fact that the patients with a heterogeneous emphysema distribution in our group had a much greater volume reduction after EBV treatment than reported previously $[6,25,28]$. Thus, surgery for LVR may have advantageous effects also in these high-risk patients, at least if provided at an experienced center. Our study is in line with the recently published, prospective, randomized controlled trial STELVIO by Klooster et al. [8] that showed very similar results regarding the changes in lung function. However, this trial found a better functional improvement in the treated patients. Of note, as in this trial, the majority of our patients were CV negative (19 of 20 treated patients). One reason why our patients failed to transfer lung functional changes into functional improvement might be due to the short interval between intervention and followup of 4-6 weeks compared to 6 months in the STELVIO trial.

According to a BODE index of 7, these patients had apart from severe functional restrictions - also a poor 
prognosis, with a predicted mortality rate of up to $80 \%$ at 52 months [29]. The BODE index is widely used as a surrogate for survival in COPD patients, especially when only a short-term follow-up is available. A recent report indicates better survival among patients with atelectasis after EBV treatment [30]; it is unclear if this holds true for this cohort, though.

Our study has important limitations that need to be addressed. Despite the fact that treatment was performed according to standardized operating procedures with a written policy, it is nevertheless a retrospective and post hoc analysis. Additionally, we did not perform a thorough analysis of the patients' quality of life. One reason why this might be important is that there might also be a placebo effect, and there was no control group. This would have been interesting additional information; however, the data finally were not available for most patients.

In conclusion, eLVR in patients with a low $\mathrm{FEV}_{1}$ and DLCO is generally feasible and safe. A pneumothorax pos- es the greatest risk for these patients. Compared to a previously published surgical cohort study, our results were not as good as those achieved with the surgical approach. Patients who qualify for the principle of reducing hyperinflation in COPD should be discussed in an interdisciplinary team on the basis of all information available at the centers capable of both surgical and endoscopic approaches.

\section{Acknowledgement}

We thank Jennifer Hockley for excellent editorial assistance.

\section{Financial Disclosure and Conflict of Interest}

F.C.T. received traveling reimbursement and speaker fees from PneumRx; P.M.L. received traveling reimbursement and speaker fees from PneumRx and PulmonX, and consulting honoraria from PulmonX. The other authors declare to have no conflict of interest.

\section{References}

$>1$ Demertzis S, Wilkens $\mathrm{H}$, Lindenmeir $\mathrm{M}$, Graeter T, Schäfers HJ: Lung volume reduction surgery for severe emphysema. J Cardiovasc Surg (Torino) 1998;39:843-847.

$\checkmark 2$ Wilkens H, Demertzis S, König J, Leitnaker CK, Schäfers HJ, Sybrecht GW: Lung volume reduction surgery versus conservative treatment in severe emphysema. Eur Respir J 2000 16:1043-1049.

3 Geddes D, Davies M, Koyama H, Hansell D, Pastorino U, Pepper J, Agent P, Cullinan P, MacNeill SJ, Goldstraw P: Effect of lungvolume-reduction surgery in patients with severe emphysema. N Engl J Med 2000;343: 239-245.

-4 Fishman A, Martinez F, Naunheim K, Piantadosi S, Wise R, Ries A, Weinmann G, Wood DE: A randomized trial comparing lung-volume-reduction surgery with medical therapy for severe emphysema. N Engl J Med 2003; 348:2059-2073.

$>5$ Kaplan RM, Sun Q, Naunheim KS, Ries AL: Long-term follow-up of high-risk patients in the National Emphysema Treatment Trial. Ann Thorac Surg 2014;98:1782-1789.

-6 Sciurba FC, Ernst A, Herth FJ, Strange C, Criner GJ, Marquette CH, Kovitz KL, Chiacchierini RP, Goldin J, McLennan G: A randomized study of endobronchial valves for advanced emphysema. N Engl J Med 2010;363 1233-1244.
7 Davey C, Zoumot Z, Jordan S, McNulty WH, Carr DH, Hind MD, Hansell DM, Rubens MB, Banya W, Polkey MI, Shah PL, Hopkinson NS: Bronchoscopic lung volume reduction with endobronchial valves for patients with heterogeneous emphysema and intact interlobar fissures (the BeLieVeR-HIFi study): a randomised controlled trial. Lancet 2015;386:1066-1073.

8 Klooster $\mathrm{K}$, ten Hacken NH, Hartman JE, Kerstjens HA, van Rikxoort EM, Slebos DJ: Endobronchial valves for emphysema without interlobar collateral ventilation. N Engl J Med 2015;373:2325-2335.

>9 Donohue JF: Minimal clinically important differences in COPD lung function. COPD 2005;2:111-124.

-10 Hartman JE, ten Hacken NH, Klooster K, Boezen HM, de Greef MH, Slebos DJ: The minimal important difference for residual volume in patients with severe emphysema. Eur Respir J 2012;40:1137-1141.

11 Puhan MA, Chandra D, Mosenifar Z, Ries A, Make B, Hansel NN, Wise RA, Sciurba F: The minimal important difference of exercise tests in severe COPD. Eur Respir J 2011;37:784-790.

-12 Miller MR, Crapo R, Hankinson J, Brusasco V, Burgos F, Casaburi R, Coates A, Enright P, van der Grinten CP, Gustafsson P, Jensen R, Johnson DC, MacIntyre N, McKay R, Navajas D, Pedersen OF, Pellegrino R, Viegi G, Wanger J: General considerations for lung function testing. Eur Respir J 2005;26:153161.
13 Miller MR, Hankinson J, Brusasco V, Burgos F, Casaburi R, Coates A, Crapo R, Enright P, van der Grinten CP, Gustafsson P, Jensen R, Johnson DC, MacIntyre N, McKay R, Navajas D, Pedersen OF, Pellegrino R, Viegi G, Wanger J: Standardisation of spirometry. Eur Respir J 2005;26:319-338.

14 Macintyre N, Crapo RO, Viegi G, Johnson DC, van der Grinten CP, Brusasco V, Burgos F, Casaburi R, Coates A, Enright P, Gustafsson P, Hankinson J, Jensen R, McKay R, Miller MR, Navajas D, Pedersen OF, Pellegrino R, Wanger J: Standardisation of the singlebreath determination of carbon monoxide uptake in the lung. Eur Respir J 2005;26: 720-735.

15 ATS statement: guidelines for the six-minute walk test. Am J Respir Crit Care Med 2002; 166:111-117.

16 Guyatt GH, Pugsley SO, Sullivan MJ, Thompson PJ, Berman L, Jones NL, Fallen EL, Taylor DW: Effect of encouragement on walking test performance. Thorax 1984;39:818-822.

-17 National Emphysema Treatment Trial Research Group: Patients at high risk of death after lung-volume-reduction surgery. N Engl J Med 2001;345:1075-1083.

18 Fuehner T, Clajus C, Fuge J, Jonigk D, Welte T, Haverich A, Greer M, Gottlieb J: Lung transplantation after endoscopic lung volume reduction. Respiration 2015;90:243-250. 
19 O'Donnell DE, Webb KA: The major limitation to exercise performance in COPD is dynamic hyperinflation. J Appl Physiol (1985) 2008;105:753-755; discussion 755-757.

-20 Eberhardt R, Herth FJ, Radhakrishnan S, Gompelmann D: Comparing clinical outcomes in upper versus lower lobe endobronchial valve treatment in severe emphysema. Respiration 2015;90:314-320.

21 Gompelmann D, Eberhardt R, Michaud G, Ernst A, Herth FJ: Predicting atelectasis by assessment of collateral ventilation prior to endobronchial lung volume reduction: a feasibility study. Respiration 2010;80:419-425.

22 Gompelmann D, Eberhardt R, Herth FJ: Collateral ventilation. Respiration 2013;85:515520.

-23 Gompelmann D, Herth FJ, Slebos DJ, Valipour A, Ernst A, Criner GJ, Eberhardt R: Pneumothorax following endobronchial valve therapy and its impact on clinical outcomes in severe emphysema. Respiration 2014;87:485-491.
24 de Oliveira HG, de Oliveira SM, Rambo RR, de Macedo Neto AV: Fissure integrity and volume reduction in emphysema: a retrospective study. Respiration 2016;91:471-479.

25 Schuhmann M, Raffy P, Yin Y, Gompelmann D, Oguz I, Eberhardt R, Hornberg D, Heussel CP, Wood S, Herth FJ: Computed tomography predictors of response to endobronchial valve lung reduction treatment. Comparison with Chartis. Am J Respir Crit Care Med 2015;191:767-774.

26 Valipour A, Slebos DJ, de Oliveira HG, Eberhardt R, Freitag L, Criner GJ, Herth FJ: Expert statement: pneumothorax associated with endoscopic valve therapy for emphysema - potential mechanisms, treatment algorithm, and case examples. Respiration 2014;87:513-521.
7 Meyers BF, Yusen RD, Guthrie TJ, Patterson GA, Lefrak SS, Davis GE, Cooper JD: Results of lung volume reduction surgery in patients meeting a national emphysema treatment trial high-risk criterion. J Thorac Cardiovasc Surg 2004;127:829-835.

28 Gompelmann D, Eberhardt R, Slebos DJ, Brown MS, Abtin F, Kim HJ, Holmes-Higgin D, Radhakrishnan S, Herth FJ, Goldin J: Diagnostic performance comparison of the Chartis System and high-resolution computerized tomography fissure analysis for planning endoscopic lung volume reduction. Respirology 2014;19:524-530.

29 Celli BR, Cote CG, Marin JM, Casanova C, Montes de Oca M, Mendez RA, Pinto Plata V, Cabral HJ: The body-mass index, airflow obstruction, dyspnea, and exercise capacity index in chronic obstructive pulmonary disease. N Engl J Med 2004;350:1005-1012.

-30 Hopkinson NS, Kemp SV, Toma TP, Hansell DM, Geddes DM, Shah PL, Polkey MI: Atelectasis and survival after bronchoscopic lung volume reduction for COPD. Eur Respir J 2011;37:1346-1351. 